\title{
EDUCAÇÃO E O ACESSO DOS NEGROS AOS CARGOS PÚBLICOS
}

\author{
Eduardo Cardoso do Socorro 1 \\ Rejane Lima de Queiroz ${ }^{2}$
}

\begin{abstract}
Resumo
A educação é o melhor caminho civilizatório de uma sociedade. Os países que estão na ponta do desenvolvimento tecnológico, econômico ou intelectual, conseguiu isso por meio dessa ferramenta essencial, não só ao crescimento econômico desses países, mas sobretudo, pela possibilidade de elevação de um povo de uma condição servil para uma condição de liberdade. Foi por meio dela que tais países reduziram seus níveis de desigualdades, superou a pobreza, e distribuiu renda de forma equitativa. Diante deste panorama, no caso do Brasil, é necessário entendermos a situação da população afrodescendente em matéria de acesso a esse bem tão essencial. E ao mesmo tempo, tão hierarquizado quando se trata do discursão dos níveis de qualidade e de acesso dessa educação aos negros e brancos, e seus efeitos no emprego, cargos de prestígio e destaque social no serviço público.
\end{abstract}

Palavras-chaves: Educação, meritocracia, racismo, emprego público.

\begin{abstract}
Education is a Society best civilizing path. Countries that are at the forefront of technological, economic or intellectual development, have achieved this through this essential tool, not only for the economic growth of these countries, but above all, for the possibility of elevating a people from a servile condition to a condition of freedom. It was through it that such countries reduced their levels of inequality, overcame poverty, and distributed income equitably. Given this scenario, in the case of Brazil, it is necessary to understand the situation of the Afro-descendant population in terms of access to this essential asset. And at the same time, so hierarchical when it comes to the discussion of the levels of quality and access of this education to blacks and whites, and its effects on employment, prestigious positions and social prominence in the public service.
\end{abstract}

Keywords: Education, meritocracy, racism, public employment.

\section{Introdução}

Este artigo tem por objeto de estudo o tema a "Educação e o Acesso dos Negros aos Cargos Públicos" numa tentativa de entender os problemas e as soluções relacionados aos acessos dos negros aos cargos públicos e como a educação tem papel fundamental nisso. Assim, tal temática é importante porque tem o propósito o combater o racismo por meio do acesso ao emprego e renda, com o

\footnotetext{
${ }^{1}$ Mestre em Ciências da Educação pela Faculdade Interamericana de Ciências Sociales (FICS). Pósgraduado em Metodologia do Ensino Superior (UNEB). Pós-graduado em Gestão Educacional (FBS).Licenciado em Geografia pela Universidade Católica do Salvador. Bacharel em Direito pela Faculdade Dois de Julho.. Atua como Advogado e Professor de Geografia na Rede Estadual de Ensino do Estado da Bahia.Email:edwjazz@hotmail.com

${ }^{2}$ Mestre em Ciências da Educação pela Faculdade Interamericana de Ciências Sociales (FICS). Pósgraduada em: Estudos Linguísticos e Literários pela UFBA; Educação, Desigualdade e Pobreza (UFBA); Gestão em Saúde (UNILAB) e Gestão Educacional pela (FFB).Licenciada em Letras Vernáculas pela Universidade Estadual de Feira de Santana (UEFS) Bacharela em Serviço Social Universidade Salvador (UNIFACS).. Atua como professora de Língua Portuguesa na rede estadual dos municípios de São Francisco do Conde e Candeias, Bahia. Email:rejanequeiroz75@gmail.com
} 
objetivo de erradicar a pobreza e a marginalização, reduzir as desigualdades sociais, promover o bem estar de todos sem preconceito de origem, raça, sexo, cor, idade.

Embora as políticas reparatórias aplicadas no Brasil forem objeto de intenso debate sociológico, político, ideológico, com discussões acaloradas nos espaços de produção científica, redes sociais, conversas do cotidiano, ainda existem lacunas a serem preenchidas por novos estudos que possam lançar luz ou elucidar aspectos ainda não abordados no tocante ao tema em destaque.

O objetivo da pesquisa é fazer uma análise no campo da Educação no tocante a aplicação das políticas afirmativas tendo como pano de fundo as implicações históricas e sociológicas da exclusão dos negros do bem-estar social. Afinal, todos nós sabemos que a Educação é um produto histórico das transformações sociais ocorridas na sociedade.

\section{A Ideologia da Meritocracia e Seu Aspecto Mitológico}

O Rap Mv Bill na sua música "Trap de Favela", já dizia com sua rima dura, certeira e contundente "sem educação não tem meritocracia". Sentença simples, cortante, mais que guarda dentro de si, uma denúncia profunda sobre a desigualdade no sistema educacional brasileiro, que põe por terra o discurso tão vociferalmente aclamado e defendido pelas camadas abastadas da classe média e da elite com o intuito de esconder um fato sombrio.

A exclusão social e a desigualdade vivida pelo sujeito no curso de sua formação escolar, intelectual e como indivíduo será determinante em relação ao lugar e o papel que ele desempenhara na estrutura social da sociedade brasileira. Esse é o grande fato que essa ideologia camufla ou máscara. Nossa proposta é desconstruir essa falácia aceita como verdade pelo conjunto da sociedade.

No plano conceitual-ideológico, e nos mostrando as feridas das meritocracias, Lívia Barbosa (2001, p. 22) conceitua meritocracia como "um conjunto de valores que postula que as posições dos indivíduos na sociedade devem ser consequência do mérito de cada um", ou seja, do reconhecimento público da qualidade das realizações individuais.

Em um discursão mais estatizante, Souza e Souza (2017, p. 722) mostram com clareza o que o componente meritocrático pode trazer de negativo, se o Estado 
se mantiver com sua inércia ideológica frente aos problemas estruturais causados por essa ideologia, pois:

\begin{abstract}
A meritocracia ignora as deficiências do Estado em oportunizar de maneira igualitária, gratuita e de qualidade a educação escolar e acadêmica a grande parte da população desprivilegiada socioeconomicamente, bem como aos negros, índios e deficientes no Brasil. A vinculação errônea de que as ações afirmativas são criadas para atenderem a falta da capacidade intelectual e cognitiva das minorias, isenta ao menos no discurso, a responsabilidade do Estado e de outras instituições, pela oferta de oportunidade ou de condições adequadas para que os sujeitos exerçam plenamente sua cidadania e o ingresso igualitário ao mercado de trabalho, assim como a uma educação pública de qualidade.
\end{abstract}

A única maneira de começar a diminuir os efeitos desse quadro aterrador da ideologia da Meritocracia sobre a subtração das oportunidades é através das políticas de ações afirmativas associada ao melhoramento gradual da escola pública, onde o estado deve arca com as responsabilidades históricas do não acesso aos despossuídos, e por ter criado barreiras institucionais de acesso a esses despossuídos. Conti e Marcato (2017, p.69) põe em evidência essa assertiva na lapidar sentença:

\footnotetext{
Assim, a justiça escolar baseada somente na meritocracia, de cunho liberal, encontra grandes dificuldades para se efetivar. A competição escolar, nesse tipo de sociedade, não suprime as desigualdades sociais, como as de classe, de raça, de gênero etc. Para o modelo meritocrático ser considerado justo e com real igualdade de oportunidades, a oferta escolar deveria ser idêntica, sem prejuízo, portanto, aos alunos menos favorecidos social e economicamente, o que, obviamente, não ocorre.
}

As autoras deixam cristalino que se querem utilizar a meritocracia como critério de acesso, ou de competitividade as vagas da Universidade ou dos empregos públicos, é necessário que a escola seja de mesma qualidade para brancos e para negros, ou como Cristóvão Buarque propõe, que o filho do rico estude na mesma escola do filho do pobre. Do contrário tudo não passa de falácia discursiva para legitimar a exclusão dos negros da boa educação, e por consequência do acesso a uma existência digna e autônoma.

\title{
Oportunidades Versus Desigualdades Numa Perspectiva Educacional
}

Dando continuidade a discursão anterior, mas ampliando com um outro enfoque. É sabido que as oportunidades de acesso a educação reduzem os efeitos da exclusão à medida que a desigualdade racial a amplia. Essas políticas de oportunidades para os negros, não têm só o viés de melhorar o nível de renda, mas também levar os negros a posições hierarquicamente brancas, pois, a 
hierarquização no emprego, renda ou cargo é problema seríssimo. A empregabilidade de alta renda é um monopólio dos brancos restando aos negros só as posições subalternas. Gomes (2001, p.27) leciona isso de forma magistral ao dizer:

No domínio do acesso ao emprego impera não somente a discriminação desabrida, mas também uma outra de suas facetas mais ignominiosas - a hierarquização -, que faz com que as ocupações de prestígio, poder e fama sejam vistos como apanágio dos brancos, reservando-se aos negros e mestiços aquelas atividades susceptíveis de realçar-Ihes a condição de inferioridade.

O problema central dessa situação é que a oportunização ao acesso as posições de prestígio denunciada por Gomes, não foram distribuídas de maneira igualitária. A alguns foram dados os meios para se elevarem profissionalmente e a outros não. Isso gerou uma distorção na representação de papéis dentro do tecido social. Para os brancos o prestígio e o destaque, para os negros a subalternidade e a invisibilidade.

Por outro lado, tratando sobre o tema da oportunidade a partir de uma concepção histórica, Osório faz uma viagem no tempo para atestar que é falsa a ideia de alguns autores dizem que o passado não interfere no presente, ou que esse passado histórico não construiu essa realidade sombria que é a exclusão dos negros. Conforme seu pensamento (2007, p.66), este diz:

\begin{abstract}
No momento da abolição, foram suprimidas as barreiras formais que a escravidão oferecia à competição dos negros com os brancos pelas posições sociais. Mas quando os portões são abertos e se faculta aos negros o ingresso na corrida, os brancos já estão quilômetros adiante. Essa é a condição inicial. Para que os negros superem a desvantagem imposta por ela, é preciso que, a cada geração, percorram uma distância maior do que a percorrida pelos brancos. Se não conseguem fazê-lo, a desigualdade racial existente no momento da abertura dos portões persiste.
\end{abstract}

Com um argumento forte, Osório desvela que mesmo com o fim das barreiras formais oriundas da escravidão, as barreiras reais sempre existiram. Dessa forma, como a população negra pode ser bem-sucedida, quando entra no jogo da competição com o déficit histórico de conhecimento?. Assim, as oportunidades geradas pela educação reduzem a racialização da pobreza, indo de encontro ao modelo liberal burguês do Estado Brasileiro, pois, existe uma concepção equivocada das desigualdades. 
Desde o império que a educação do Brasil é um sistema de privilégios. Nesse período só a elite imperial tinha acesso à educação, saber ler era um artigo de luxo e poucos tinham esse artigo. Saber ler também era sinônimo de poder e só alguns poucos o tinham. Cabe refletir e procurar apontar as bases desse sistema de exclusão imaginado desde muitos séculos. Do período da escravidão até a sua extinção, é preciso refletir profundamente como a educação da população afrodescendente foi gestado. Sobre tal situação Gonçalves (2000, p.325) nos oferece uma reflexão interessante acerca do assunto:

Não é mais possível continuar associando mecanicamente sucesso escolar e escolaridade dos pais. A questão é saber como avós analfabetos influenciaram a pouca escolarização de seus filhos, e como estes, apesar da pouca escolaridade, têm estimulado suas gerações futuras a terem êxito na escola.

O autor deixa bem claro que o analfabetismo era o DNA dos avós dos filhos e netos dos escravizados. Uma marca que ainda persiste hoje de forma mais branda, mesmo com os avanços da universalização da educação. Gonçalves (2000, p. 325) constata em seus estudos que "outros negros mais idosos (entre 60 e 80 anos ou mais), cuja infância e juventude estão mais próximas do início do século $X X$, padecem de altíssimos índices de analfabetismo. Por exemplo, em um total de 3 milhões".

A segmentação escolar baseada no mérito e na condição socioeconômica é um estorvo que cria um buraco profundo nas relações de classe e raciais entre indivíduos. As diferenças educacionais são imensas, Osório (2005, p.21) insiste em dizer que:

\begin{abstract}
As diferenças educacionais entre negros e brancos têm múltiplas causas e efeitos duradouros no curso da vida. Sabe-se que as crianças negras sofrem, inicialmente, por sua origem social relativamente mais pobre em todos os sentidos, o que diminui suas chances de ingressar no sistema educacional e ainda mais de uma vez realizada a chance de ingresso, frequentar uma boa escola. Isso afetará suas oportunidades na vida adulta e, por antecipação, as de seus descendentes.
\end{abstract}

A origem social pobre segundo o autor é fator determinante para que o ingresso no sistema de competição educacional já seja desigual para a criança negra. Tudo nesse mecanismo conspira para que o fracasso talvez chegue mais rápido as portas dessa criança. A mistura de pobreza, vulnerabilidade e dependência de um sistema de ensino deficitário e cruel, coloca nas costas das crianças e jovens negros o peso de um futuro incerto e talvez pouco promissor. 


\section{O Papel das Cotas Raciais educacionais na Redução das Desigualdades no Mundo do Trabalho}

O racismo é uma praga que se diluiu em todos os aspectos da vida do negro no Brasil. Se fez presente nas relações socioafetivas com o branqueamento. $\mathrm{Na}$ educação com a segregação ao bom ensino. Nos níveis de renda com a hierarquização do emprego. Na saúde precária oferecida a eles nos hospitais e postos de saúde sucateados, no trabalho e seu acesso, seja na iniciativa privada ou serviço público.

Observa-se que há um afogamento sistemático dos seus direitos e da sua cidadania. Talvez a desigualdade no mundo do trabalho seja a mais evidente, dentre as outras. Já que cedo ou tarde os indivíduos entrarão no mercado de trabalho e competirão pelos postos de emprego. Cerqueira e Moura (2013, p.13) faz uma radiografia dessa situação dizendo:

Se, do ponto de vista da demanda por trabalho, o racismo bloqueia o
acesso a oportunidades e interdita o crescimento profissional, efeitos
igualmente maléficos podem ocorrer pelo lado da oferta de trabalho. A
repetição subliminar do estereótipo do negro como um ser inferior, inapto ao
trabalho qualificado especializado, e muitas vezes perigoso e criminoso, que
é reproduzida cotidianamente por diferentes manifestações culturais, não
apenas agride e enfraquece a autoestima dos afrodescendentes, sobretudo
os jovens, como pode gerar um processo de reificação que descaracteriza a
individualidade do negro e reforça uma imagem distorcida que o mesmo faz
de si.

Os dois autores deixam claro algo contundente. O racismo "interdita o crescimento profissional". $\mathrm{Na}$ iniciativa privada isso é algo que ocorre quiçá com frequência. Quantos negros mais experientes e competentes que determinados brancos, são preteridos de postos de comando ou promovidos por serem negros? Um caso típico é o de Heraldo Pereira jornalista da Globo. Super competente no seu trabalho como ancora de diferentes jornais da Emissora, mas que sempre foi utilizado com uma espécie de "tapa buraco" nos finais de semana no Jornal Nacional. Jornalista mais jovens e menos experientes que ele, já estão em posições de titular na Emissora, a exemplo de Dony De Nuccio.

Com argumentos semelhantes e muito reais sobre a condição do negro no acesso ao mercado de trabalho, Hasenbalg e Silva (1992 apud Osorio, 2000, p.54) vai na mesma linha de pensamento de Cerqueira e Moura, quando analisa os critérios para os negros entrarem no mercado de trabalho ao dizer: 
há um processo de competição social que se desenvolve em etapas, acumulando desvantagens que impedem igualdade de chances. A cor, como critério de seleção no mercado do trabalho, também varia segundo o perfil da ocupação. Aquelas ocupações mais voltadas ao contato direto com o público estão mais suscetíveis à exclusão dos negros, ao contrário de posições manuais. Também é forte a hipótese de que quanto mais alta a ocupação está na hierarquia ocupacional, mais refratária à absorção de negros. E de que quanto mais alto for o nível educacional exigido, maior será a discriminação observada no mercado de trabalho.

Essa passagem lapidar do referido autor desnuda por completo o mito da democracia racial. Este nos oferece uma quantidade considerável de argumentos que põe por terra a chamada igualdade de mérito no mercado de trabalho e deixa em evidência as vísceras do sistema de exclusão do negro no mercado de trabalho.

\section{Considerações Finais}

Por conseguinte, uma mistura de políticas públicas estatais podem ser um dos remédios para o racismo no campo do acesso dos afrodescendentes aos cargos públicos. Hoje tanto o Estado como as empresas, têm uma grande responsabilidade frente ao combate ao racismo, a discriminação racial e o preconceito.

O que se é preciso é uma mudança radical de mentalidade dessas instituições. A atitude contra o racimo institucional é um ponto de inflexão contra um passado histórico de exclusão brutal de uma população que contribuiu para produção de riquezas para o país, mas na hora de usufruir dessa riqueza foram barradas no baile.

Dessa forma, é evidente que o principal resultado encontrado no processo de análise do acesso negro aos cargos públicos é que as políticas de reparação são um veículo conduto de mudanças institucionais frente as desigualdades raciais. E essas mudanças representam uma ruptura no ciclo de exclusão racial historicamente perpetuada no país.

\section{Referencias:}

BARBOSA, Lívia. Igualdade e meritocracia: a ética do desempenho nas Sociedades modernas. 3 ed. Rio de Janeiro: Editora FGV, 2001.

BIIL, Mv. Trap de Favela. [s.I.]:Universal Music Group. 2018.

CARVALHO, José Jorge de. O confinamento racial do mundo acadêmico brasileiro. São Paulo: REVISTA USP, 2006. 
CERQUEIRA, Daniel R. C.; MOURA, Rodrigo Leandro de. Vidas Perdidas e Racismo no Brasil. Brasília: Nota Técnica. IPEA, 2013.

CONTI, Celso Luiz Aparecido; MARCATO, Célio Tiago. Justiça e Igualdade na Escola: A Falácia da Meritocracia. São Carlos: UFSCar ..DEVIR EDUCAÇÃO, 2017.

GOMES, Joaquim B. Barbosa. A recepção do instituto da ação afirmativa no Direito Constitucional brasileiro. Brasília: Revista de Informação Legislativa, 2001.

GOMES, Joaquim B. Barbosa. Ação Afirmativa \& Princípio Constitucional da Igualdade. Rio de Janeiro: Editora Renovar, 2001.

GOMES, Joaquim Barbosa. Instrumentos e Métodos de Mitigação da Desigualdade em Direito Constitucional e Internacional. Rio de Janeiro: 2000. Disponível em: http//www.mre.gov.br.

GOMES, Joaquim Benedito Barbosa; SILVA, Fernanda Duarte Lopes Lucas. As Ações Afirmativas e os processos de promoção da igualdade efetiva. Seminário Internacional As Minorias e o Direito. Brasília: Série Cadernos do CEJ, 2001.

GONÇALVES, Luiz Alberto Oliveira. Negros e Educação no Brasil. In: C. G. VEIGA; E. M. T. LOPES; L. M. F. FILHO (Orgs.). 500 Anos de Educação no Brasil. 2. Ed. Belo Horizonte: Autêntica, 2000.

OSÓRIO, Rafael Guerreiro. A Geração 80: Um Documentário Estatístico Sobre a Produção das Diferenças Educacionais entre Negros e Brancos. In: BARBOSA M. L. de O.; BELTRÃO, K. I.; FERRÃO M. E.; SOARES, S. (Orgs). Os Mecanismos de Discriminação Racial nas Escolas Brasileiras. [s.I.]:IPEA, 2005.

OSÓRIO, Rafael Guerreiro. Desigualdade Racial e Mobilidade Social no Brasil: Um Balanço Das Teorias. In: THEODORO, Mário (Org.). As Políticas Públicas e a Desigualdade Racial no Brasil 120 anos após a Abolição. 1.ed. [s.I]:IPEA. Novembro de 2008.

SOUZA, Janyne Barbosa de; SOUZA, Fernanda Dione Sales de. As Cotas Raciais, as Ações Afirmativas e a Meritocracia na Universidade Estadual do Sudoeste da Bahia-UESB. In: XII Colóquio Nacional e V Colóquio Internacional do Museu Pedagógico. Salvador: UESB,,2017. 